\title{
Block of AMPA Receptor Desensitization by a Point Mutation outside the Ligand-Binding Domain
}

\author{
Maria V. Yelshansky, Alexander I. Sobolevsky, Claudia Jatzke, and Lonnie P. Wollmuth \\ Department of Neurobiology and Behavior, State University of New York at Stony Brook, Stony Brook, New York 11794-5230
}

\begin{abstract}
Desensitization of ionotropic glutamate receptors (GluRs), specifically the AMPA receptor subtype, shapes the postsynaptic response at certain synapses in the brain. All known mechanisms that alter desensitization, either pharmacological or mutational, are associated with the ligand-binding domain. Here we report that substitution of a conserved positively charged arginine (R) with a negatively charged glutamate in the linker between the pore-forming M3 segment and the S2 lobe, a region outside the ligand-binding domain, blocks desensitization in homomeric AMPA receptors composed of GluR- $B_{i}$ subunits. A charge-reversing substitution of a glutamate adjacent to this conserved $\mathrm{R}$ enhanced desensitization, consistent with these effects attributable to electrostatics. Homologous substitutions of the conserved R in GluR- $B_{0}$, GluR- $A_{i}$ and the kainate receptor GluR-6 subunits produced comparable but less visible effects on desensitization. Subunit specificity was also apparent for accessibility of substituted cysteines in the M3-S2 linker, suggesting that this part of the channel is not structurally identical in different GluRs. Additionally, reactivity with a sulfhydryl-specific reagent was state dependent, suggesting that the conformations of the nonconducting closed and desensitized states are different at the level of the M3-S2 linker. Our results therefore represent the first identification of elements outside the ligand-binding domain affecting desensitization in non-NMDA receptor channels and suggest that electrostatic interactions involving charged residues in the M3-S2 linker influence channel gating in a subunit- and subtype-specific manner.
\end{abstract}

Key words: channel gating; desensitization; ligand-binding domain; M3 segment; M3-S2 linker; substituted cysteine accessibility method

\section{Introduction}

In the continued presence of glutamate, ionotropic glutamate receptors (GluRs), specifically AMPA receptor (AMPAR) and kainate receptor (KAR) subtypes, undergo fast and strong desensitization, a process in which the associated ion channel enters into a nonconducting (desensitized) state. At present, all known mechanisms that alter desensitization in non-NMDA receptors (non-NMDARs), either pharmacological (Partin et al., 1995) or mutational (Stern-Bach et al., 1998; Banke et al., 2001; Partin, 2001), are associated directly with the ligand-binding domain. Structurally and functionally, the ligand-binding domain of GluRs is organized as a pair of dimers (Armstrong and Gouaux, 2000; Mansour et al., 2001; Robert et al., 2001) with desensitization possibly reflecting dedimerization of a dimer (Sun et al., 2002). Hence, binding of cyclothiazide (CTZ) (Partin et al., 1995) as well as a leucine-to-tyrosine substitution (Stern-Bach et al., 1998) apparently block desensitization by stabilizing a dimer interface.

Received March 2, 2004; revised April 5, 2004; accepted April 5, 2004.

This work was supported by National Institutes of Health R01 Grants NS39102 from the National Institute of Neurological Disorders and Stroke and MH066892 from the National Institute of Mental Health (L.P.W.) and National Science Foundation-NATO Grant 0108063 (M.V.Y.). We thank W. Raab, M. Prieto, and L. Rooney for technical assistance, T. Kuner for assistance in obtaining GluR- $B_{0}$ DNA, and S. Iordanskiy for help with molecular biology.

Correspondence should be addressed to Dr. Lonnie P. Wollmuth at the above address. E-mail: Iwollmuth@notes1.cc.sunysb.edu.

C. Jatzke's present address: Department of Preclinical Research and Development, Merz Pharmaceuticals GmbH, Eckenheimer Landstrasse 100, 60318 Frankfurt/Main, Germany.

DOI:10.1523/JNEUROSCI.0757-04.2004

Copyright $\odot 2004$ Society for Neuroscience $\quad$ 0270-6474/04/244728-09\$15.00/0
In contrast to the ligand-binding domain, little is known about the contribution of the ion channel to the process of desensitization. In GluR subunits, the ligand-binding domain is formed by the proximal part of the $\mathrm{N}$ terminus ( $\mathrm{S} 1$ lobe) and the large loop between transmembrane segments M3 and M4 (S2 lobe) (Fig. $1 \mathrm{~A}$ ). All four hydrophobic segments (M1-M4) apparently contribute to the ion channel (Kuner et al., 1996, 2001; Beck et al., 1999), with M3 representing the major structural element lining the pore and involved in channel opening and closure (Kohda et al., 2000; Jones et al., 2002; Sobolevsky et al., 2002, 2003). Accordingly, the linker between M3 and the ligandbinding domain, the M3-S2 linker, transfers the conformational changes in the ligand-binding domain to M3, but its structural and functional contribution to gating in non-NMDARs is unknown.

Figure $1 B$ shows a sequence alignment of the M3-S2 linker and adjacent regions in non-NMDAR subunits. This linker is positioned downstream from SYTANLAAF, the most highly conserved motif in GluRs (Kuner et al., 2003), and is also conserved to some extent. Notable in this regard is the presence in all subunits of a highly conserved positively charged arginine (R). This arginine and an adjacent negatively charged glutamate (E) in AMPAR subunits influence $\mathrm{Ca}^{2+}$ permeation (Jatzke et al., 2003) and presumably are positioned in the ion conduction pathway. Recent evidence has also suggested that charged residues in linker regions in $\mathrm{GABA}_{\mathrm{A}}$ (Kash et al., 2003) and voltage-gated channels (Larsson and Elinder, 2000) affect channel gating. We therefore investigated the functional significance of the conserved arginine 


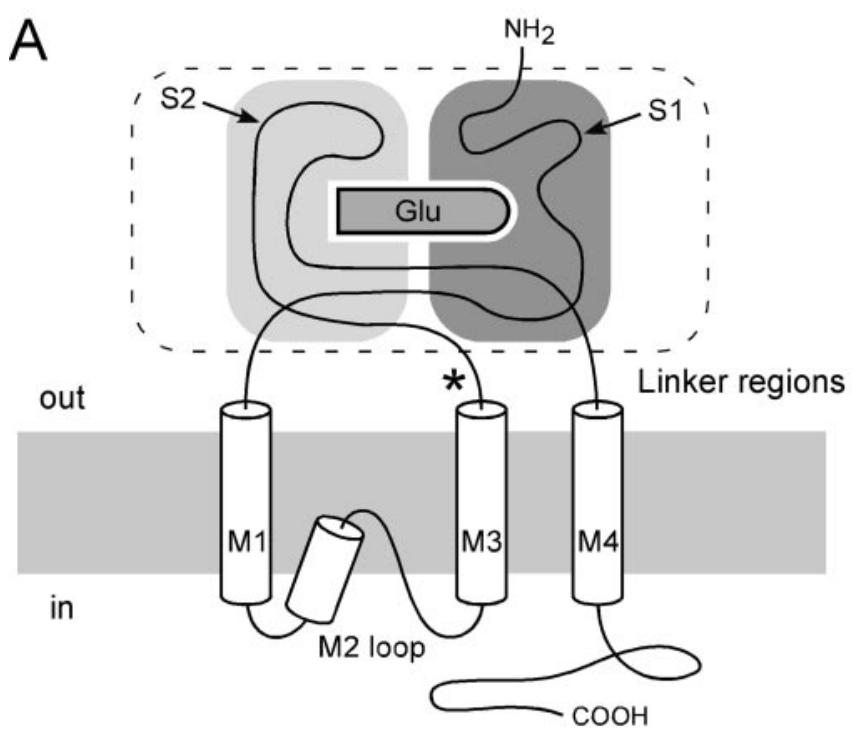

B

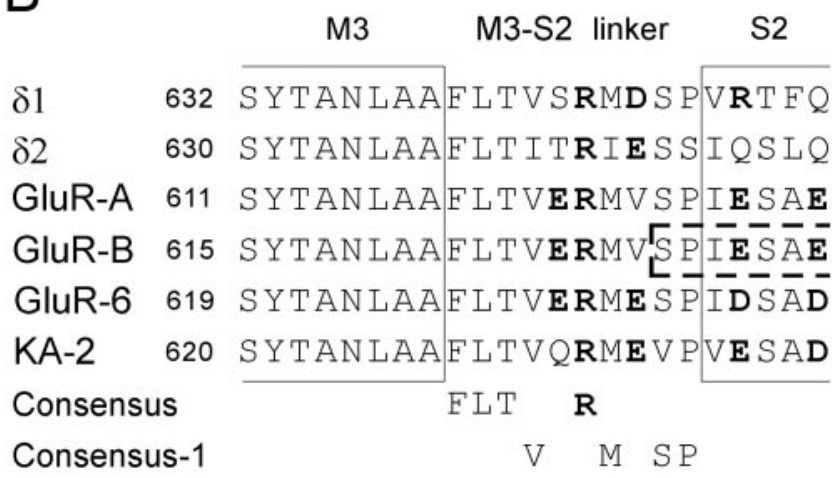

Figure 1. M3-S2 linker in GluRs. A, Topology of a GluR subunit. Presumed $\alpha$-helical regions of the membrane-spanning segments M1-M4 and the pore loop M2 are shown as open cylinders. The $\mathrm{S} 1$ (N-terminal to M1) and S2 (between M3 and M4) lobes constitute the ligandbinding core (dashed box), for which a crystal structure exists (Armstrong et al., 1998; Armstrong and Gouaux, 2000). The large $\mathrm{N}$-terminal domain is not shown. The asterisk indicates the approximate location of positions mutated in the present study. $B, A$ Amino acid sequence of non-NMDAR subunits within and around the M3-S2 linker. Subunits shown include $\delta(\delta 1, \delta 2)$, AMPAR (GluR-A, GluR-B), and low-affinity (GluR-6) and high-affinity (KA-2) KAR. Within AMPAR and low- and high-affinity KAR subunits, these regions are completely conserved. Residues conserved in all non-NMDAR subtypes (Consensus) or in all subtypes except for one (Consensus-1) are shown under the alignment. Charged residues are shown in bold. Positions within the dashed box are resolved in the crystal structure of the GluR-B ligandbinding core (Armstrong et al., 1998; Armstrong and Gouaux, 2000).

as well as other charged residues in the M3-S2 linker using sitedirected mutagenesis, fast agonist application, and chemical modification. We find that charged residues in the M3-S2 linker are involved in electrostatic interactions that affect channel desensitization in a subunit- and subtype-specific manner.

\section{Materials and Methods}

Molecular biology and heterologous expression

AMPAR subunits are named using the nomenclature of Seeburg (1993) with the flip/flop cassette indicated by the i/o subscript. Numbering of amino acids is for the mature protein. The KAR subunit, GluR-6, was fully edited within the M1 segment (V and C) (Kohler et al., 1993). Point mutations in GluR- $\mathrm{A}_{\mathrm{i}}$ or GluR- $\mathrm{B}_{\mathrm{i} / \mathrm{o}}$, either with glutamine $(\mathrm{Q})$ or asparagine $(\mathrm{N})$ at the $\mathrm{Q} / \mathrm{R}$ site, and GluR-6 subunits were generated by a QuikChange site-directed mutagenesis kit (Stratagene, La Jolla, CA) or by other PCR-based methods using Platinum Pfx DNA polymerase (In- vitrogen, Carlsbad, CA) or Pfu poly DNA polymerase (Stratagene). Positive clones were subcloned back into the respective wild-type clone present either in the eukaryotic expression vector pRK or a pSP64Tderived vector optimized for expression in Xenopus laevis oocytes. All constructs were sequenced over the entire length of the replaced fragment. cRNA was transcribed and capped for each expression construct using SP6 RNA mMessage kit (Ambion Inc., Austin, TX) and examined electrophoretically on a denaturating agarose gel. RNA concentrations were determined by ethidium bromide stain of the gel relative to an RNA molecular weight marker. Dilutions of RNA $(0.01-0.1 \mu \mathrm{g} / \mu \mathrm{l})$ were prepared to achieve optimal expression.

Channels were expressed transiently either in human embryonic kidney 293 (HEK 293) cells or in Xenopus laevis oocytes. HEK 293 cells were transfected with GluR subunits using FuGene 6 (Roche Molecular Biochemicals, Indianapolis, IN). A vector for enhanced green fluorescent protein (pEGFP-C1; Clontech, Palo Alto, CA) was cotransfected at a ratio of 1:9 (pEGFP-C1:GluR subunit). Oocytes were prepared, injected, and maintained as described (Wollmuth et al., 1996; Sobolevsky et al., 2002). Recordings were made $1-6 \mathrm{~d}$ after transfections or injections.

\section{Current recording}

Currents from HEK 293 cells were recorded at room temperature (20$23^{\circ} \mathrm{C}$ ) using an EPC-9 amplifier with PULSE software (HEKA Elektronik, Lambrecht, Germany), low-pass filtered at $2.9 \mathrm{kHz}$, and digitized at 10 $\mathrm{kHz}$. Pipettes had resistances of 2-4 M $\Omega$ when filled with the pipette solution and measured in the $\mathrm{Na}^{+}$reference solution. We did not use series resistance compensation. External solutions were applied using a piezo-driven double-barrel application system. One barrel contained the external solution, and the other barrel contained the same solution with added glutamate (1-3 mM, unless otherwise noted). The open tip response (10-90\% rise time) of the application system was $\sim 350 \mu \mathrm{sec}$. Although suitable to study desensitization kinetics, this solution exchange was too slow to measure deactivation rates in wild-type AMPARs.

Our standard intracellular (pipette) solution consisted of (in mM): 140 $\mathrm{KCl}, 10$ HEPES, and 1 BAPTA, pH $7.2(\mathrm{KOH})$. The standard external solution consisted of (in mM): $140 \mathrm{NaCl}, 10$ HEPES, $1.8 \mathrm{CaCl}_{2}$, and 1 $\mathrm{MgCl}_{2}, \mathrm{pH} 7.2(\mathrm{NaOH})$. In some instances, we added CTZ (30-200 $\mu \mathrm{M}$; stock solution was in $100 \mathrm{~mm} \mathrm{NaOH}$ ) to the external solutions for AMPARs to minimize desensitization. Unless otherwise noted, all chemicals were obtained from Sigma (St. Louis, MO) or J. T. Baker Company (Phillipsburg, NJ).

We recorded whole-cell currents in Xenopus oocytes at room temperature $\left(20-23^{\circ} \mathrm{C}\right)$ using a two-electrode voltage clamp (TEV-200A; Dagan Corp., Minneapolis, MN) with Cell Works software (npi Electronic, Tamm, Germany). Microelectrodes were filled with $3 \mathrm{~m} \mathrm{KCl}$ and had resistances of 1-4 M $\Omega$. To minimize solution exchange rates, we used a narrow flow-through recording chamber with a small volume of $\sim 70 \mu \mathrm{l}$. The external solution consisted of (in $\mathrm{mM}$ ): $115 \mathrm{NaCl}, 2.5 \mathrm{KCl}, 0.18$ $\mathrm{CaCl}_{2}$, and 10 HEPES, pH $7.2(\mathrm{NaOH})$. Glutamate (1 mM), CNQX, CTZ, and 2-(trimethylammonium)ethyl methanethiosulfonate (MTSET) were applied with the bath solution. MTSET was purchased from Toronto Research Chemicals (Toronto, Ontario, Canada).

\section{Experimental protocols}

Kinetics. To measure kinetics, we recorded currents in outside-out patches excised from HEK 293 cells, although sometimes (where noted) in the whole-cell mode. In some instances, specifically when current amplitudes were small, we averaged 3-10 current records. To determine the rate and extent of desensitization, we rapidly applied glutamate for $100-1000 \mathrm{msec}$ typically at $-60 \mathrm{mV}$. Time constants of desensitization $\left(\tau_{\text {des }}\right)$ were determined by fitting the current decay with a single exponential function. We contrasted the extent of desensitization in several different ways. On the basis of steady-state $\left(I_{\mathrm{ss}}\right)$ and peak $\left(I_{\mathrm{p}}\right)$ current amplitudes recorded in the same solution, we calculated the percentage of desensitization $\left[\%\right.$ des $\left.=100 \times\left(1-I_{\mathrm{ss}} / I_{\mathrm{p}}\right)\right]$. We also used these amplitudes to calculate the plateau/peak ratio (plateau/peak $\left.=I_{\mathrm{ss}} / I_{\mathrm{p}}\right)$. Alternatively, we calculated the percentage desensitization using CTZ as a reference $\left(\% d e s_{\text {CTZ }}\right)$, comparing steady-state current amplitudes in the control solution $\left(I_{\mathrm{ss}}\right)$ with peak amplitudes recorded in the same solution 
but with added CTZ $\left(I_{\mathrm{p}(\mathrm{CTZ})}\right)\left[\%\right.$ des $\left._{\mathrm{CTZ}}=100 \times\left(1-I_{\mathrm{ss}} / I_{\mathrm{p}(\mathrm{CTZ})}\right)\right]$. Peak current amplitudes measured in a solution without $\left(I_{\mathrm{p}}\right)$ or with $\left(I_{\mathrm{p}(\mathrm{CTZ})}\right)$ added CTZ were used to calculate changes in current amplitudes $\left(\%\right.$ inc $\left.=100 \times I_{\mathrm{p}(\mathrm{CTZ})} / I_{\mathrm{p}}\right)$.

Recovery from desensitization $\left(\tau_{\text {rec }}\right)$ was estimated using a two-pulse protocol. After a base application of glutamate (100 or $200 \mathrm{msec}$ in length), a 5 msec test application of glutamate was applied at increasing times thereafter. The peak current during the test application $\left(I_{\text {test }}\right)$ was normalized either to the peak current of the base application $\left(I_{\mathrm{p}}\right)\left(I_{\text {norm }}=\right.$ $\left.I_{\text {test }} / I_{\mathrm{p}}\right)$ or to only the desensitizing portion of the current during the base application $\left[I_{\text {norm }}=\left(I_{\text {test }}-I_{\text {ss }}\right) /\left(I_{\mathrm{p}}-I_{\mathrm{ss}}\right)\right]$. Normalized currents (expressed as a percentage, $\%$ rec $\left.=100 \times I_{\text {norm }}\right)$ were plotted as a function of time after the end of the base application and fitted with a single exponential to derive $\tau_{\text {rec }}$.

Glutamate concentration dependence. Concentration-response curves were measured in the whole-cell mode in the presence of $30 \mu \mathrm{M} \mathrm{CTZ.}$ Solutions containing various concentrations of glutamate $(0.001-10$ $\mathrm{mm}$ ) were applied to cells held at $-60 \mathrm{mV}$. Current amplitudes normalized to the maximal response were plotted as a function of concentration and fitted with the Hill equation, $1 /\left(1+\left(\mathrm{EC}_{50} /[\mathrm{Glu}]\right)^{n}\right)$, where $\mathrm{EC}_{50}$ is the concentration to achieve half-maximal response, and $n$ is the Hill coefficient.

Substituted cysteine accessibility method. Cysteine-substituted GluR channels were probed from the extracellular side of the membrane with the positively charged MTSET. MTSET-containing solutions were prepared, stored, and applied as described previously (Sobolevsky et al., 2002). Accessibility of substituted cysteines was determined using steadystate reaction protocols (Sobolevsky et al., 2002).

\section{Data analysis}

All curve fitting was done using Igor Pro (WaveMetrics, Lake Oswego, OR). Results are reported and shown graphically as mean \pm SEM. An ANOVA was used to test for statistical differences, with the Tukey test used for multiple comparisons. Significance was assumed if $p<0.05$. In figures, and unless otherwise noted, filled bars indicate values statistically different from those for wild type.

\section{Results}

\section{Opposite charge substitutions of the conserved arginine in the M3-S2 linker}

To study gating in AMPAR and KAR subtypes, we recorded glutamate-activated currents from wild-type and mutant channels in outside-out patches isolated from HEK 293 cells using rapid solution exchange. Figure $2 A-C$ (left traces) shows currents recorded from wild-type GluR- $A_{i}$, GluR- $B_{i}$, and GluR-6 channels. During the glutamate application (filled bars, $100 \mathrm{msec}$ ), the current rapidly reached peak amplitude and then strongly decayed, reflecting the process of desensitization. For wild-type channels, the rate of desensitization $\left(\tau_{\mathrm{des}}\right)$ was fast with its extent, expressed as a percentage (\%des; see Materials and Methods), always $>96 \%$. Mean values for $\tau_{\text {des }}, \%$ des, plateau/peak ratio, and the time constant for recovery from desensitization $\left(\tau_{\text {rec }}\right)$ for wildtype channels including GluR- $\mathrm{B}_{\mathrm{o}}$ are summarized in Table 1 . These values are comparable with those reported previously (Mosbacher et al., 1994; Dingledine et al., 1999; Sun et al., 2002).

Figure $2 A-C$ (right traces) shows currents for mutant channels, where the conserved positively charged $\mathrm{R}$ in the M3-S2 linker is replaced with the negatively charged $\mathrm{E}(\mathrm{R} \rightarrow \mathrm{E}$ substitution). Surprisingly, the extent of desensitization, especially for the AMPAR subtypes, was greatly attenuated. The strongest effect was observed for GluR- $B_{i}$ (R628E), in which only $\sim 15 \%$ of the peak current desensitized compared with $\sim 97 \%$ in wild-type GluR- $\mathrm{B}_{\mathrm{i}}$ (Table 1). The $\mathrm{R} \rightarrow \mathrm{E}$ substitution in GluR-A $\mathrm{A}$ (\%des $\simeq$ $58 \%$ ), GluR-B (\%des $\simeq 58 \%$ ), and GluR-6 (\%des $\simeq 91 \%$ ) produced less dramatic reductions in the extent of desensitization. However, the plateau/peak ratio was increased to approximately the same extent (20-30 times) for all subunits (Table 1), indicat-
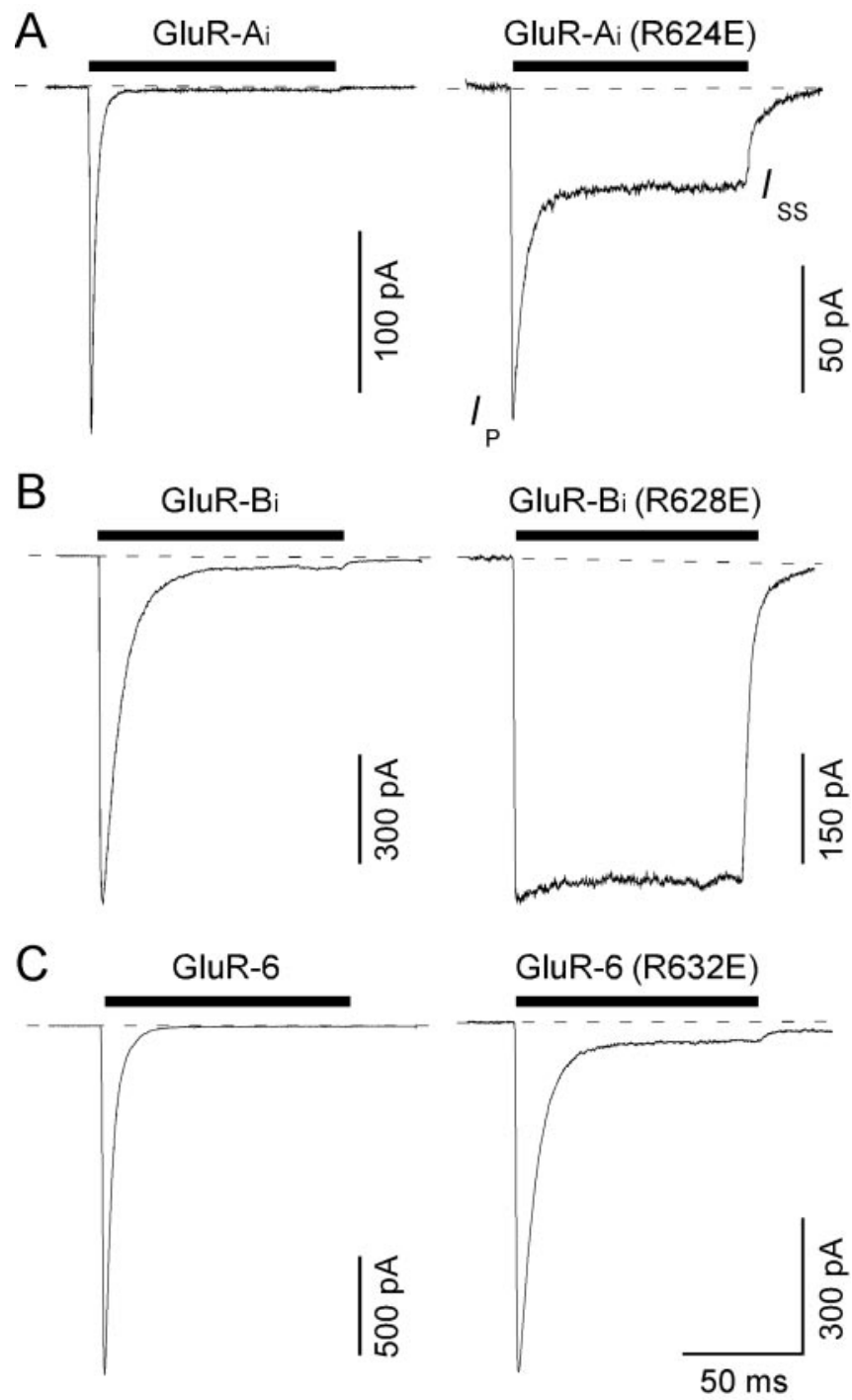

Figure 2. Effect of the $R \rightarrow E$ charge reversal in the M3-S2 linker on glutamate-activated currents in AMPAR and KAR channels. Glutamate-activated currents in outside-out patches isolated from HEK 293 cells expressing wild-type (left traces) or mutant (right traces) GluR-A $(A), G$ luR- $B_{i}(B)$, and GluR-6 $(C)$ channels are shown. The mutant channels have the positively charged arginine $(R)$ in the M3-S2 linker replaced by a glutamate $(E)(R \rightarrow E$ substitution). Currents were elicited by a $100 \mathrm{msec}$ application of glutamate ( $3 \mathrm{~mm}$; filled bar) at a holding potential of $-60 \mathrm{mV}$. Current amplitudes were measured either at the peak $\left(V_{\mathrm{p}}\right)$ or near the end of the glutamate applications when they reached steady-state $\left(l_{s s}\right)$. Dashed lines show zero current level. The time scale is the same for all panels.

ing that the quantitative effect of the $\mathrm{R} \rightarrow$ E substitution on GluR desensitization depends on the extent of desensitization in the respective wild type. In all backgrounds, the $\mathrm{R} \rightarrow \mathrm{E}$ substitution slowed the rate of desensitization by approximately twofold compared with their respective wild type.

In summary, the $\mathrm{R} \rightarrow \mathrm{E}$ substitution produces the same qualitative effects on channel gating in all backgrounds but with strong quantitative differences in reducing the extent of desensitization between GluR subunits and subtypes. Because the strongest effect of the $\mathrm{R} \rightarrow \mathrm{E}$ substitution on \%des was found in the GluR- $B_{i}$ background, we mainly focused on this subunit to address the basis of the nondesensitizing phenotype.

\section{The $\mathrm{R} \rightarrow$ E substitution disrupts desensitization}

One potential explanation for the results shown in Figure 2 is that the $\mathrm{R} \rightarrow \mathrm{E}$ substitution destabilizes the desensitized state. Exper- 


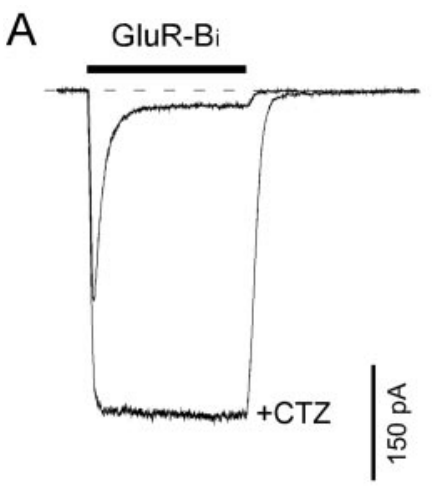

B

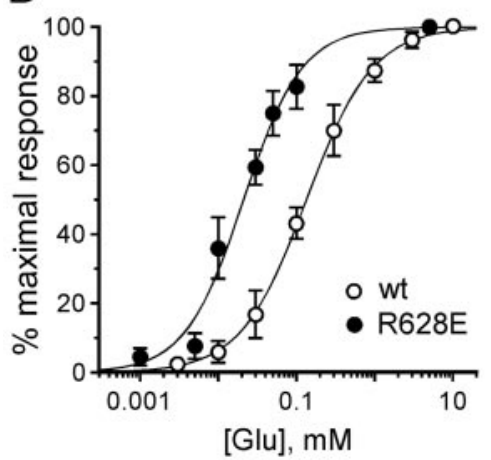

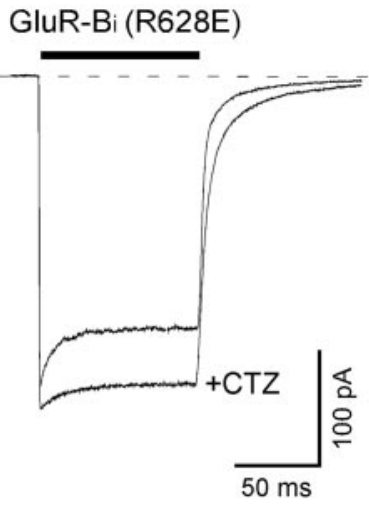

C

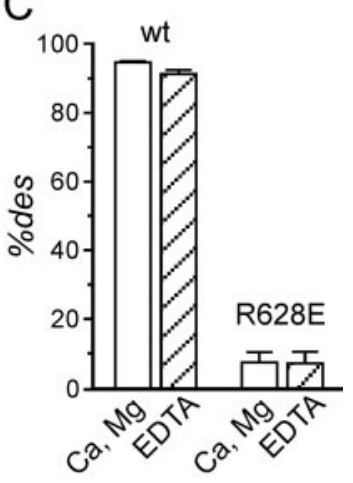

Figure 3. The $\mathrm{R} \rightarrow \mathrm{E}$ substitution disrupts desensitization in GluR- $\mathrm{B}_{\mathrm{i}}$ channels. $A$, Superimpositions of glutamate-activated currents for wild-type (left traces) and mutant $(R \rightarrow E$; right traces) GluR- $B_{i}$ channels recorded either in the absence or in the presence of $30 \mu \mathrm{m}$ CTZ. Currents were elicited by a $100 \mathrm{msec}$ application of glutamate ( $3 \mathrm{~mm}$; filled bar) at a holding potential of $-60 \mathrm{mV}$. B, Glutamate concentration response curves for wild-type (wt; open symbols) and mutant ( $R \rightarrow E$; filled symbols) GluR- $B_{i}$ channels. The solid lines are a fitted Hill equation with an $\mathrm{EC}_{50}$ of $134 \pm 3 \mu \mathrm{m}(n=5)$ for wild type and $24 \pm 2 \mu \mathrm{m}(n=4)$ for GluR-B $\mathrm{B}_{\mathrm{i}}$ (R628E). $C$, Average extent of desensitization, \%des, for wild-type and GluR- $B_{i}$ (R628E) channels measured in the absence or presence of $100 \mu \mathrm{m}$ EDTA. Currents were recorded either in our standard external solution containing $1.8 \mathrm{~mm} \mathrm{Ca}^{2+}$ and $1 \mathrm{~mm} \mathrm{Mg}^{2+}$ or in the same solution but with 100 $\mu \mathrm{M}$ EDTA and no added divalent cations.

iments shown in Figure 3 support this general idea. Figure $3 A$ compares current amplitudes in the absence and presence of CTZ $(30-200 \mu \mathrm{M})$, an allosteric modulator that attenuates desensitization in the flip form of AMPAR subunits (Partin et al., 1993, 1994). For wild-type channels, CTZ potentiated peak current amplitudes, on average by $\sim 137 \%(\%$ inc $=137 \pm 11 \%$; $n=7$; mean \pm SEM, number of patches), as has been found previously

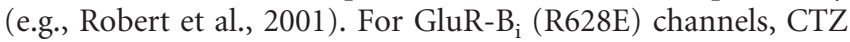
did not potentiate peak current amplitudes (\%inc $=103 \pm 2 \%$; $n=10$ ). Furthermore, the extent of desensitization using peak current amplitudes in CTZ as a reference (\%des ${ }_{\text {CTZ }}$; see Materials and Methods) was $97.7 \pm 0.4 \%$ for wild-type and $15.6 \pm 2.3 \%$ for the $\mathrm{R} \rightarrow$ E-substituted channels. These values are comparable with the \%des recorded in the absence of CTZ ( $~ 96.5$ and $\sim 14.5 \%$, respectively; Table 1 ). The experiments with CTZ therefore argue against the alternative that the $\mathrm{R} \rightarrow \mathrm{E}$ substitution might somehow favor the desensitized state.

Block of desensitization by the leucine-to-tyrosine substitution in the ligand-binding domain (Robert et al., 2001) or CTZ treatment (Partin et al., 1994) increases the apparent glutamate affinity. Consistent with the idea that $\mathrm{R} \rightarrow$ E substitution disrupts desensitization, GluR-B $\mathrm{B}_{\mathrm{i}}(\mathrm{R} 628 \mathrm{E})$ channels show an increased apparent affinity for glutamate $\left(\mathrm{EC}_{50} \simeq 24 \mu \mathrm{M}\right)$ compared with that for wild type $\left(\mathrm{EC}_{50} \simeq 134 \mu \mathrm{M}\right)$ (Fig. $3 B$ ).
Table 1. Desensitization properties of wild-type and mutant AMPAR and KAR channels

\begin{tabular}{lrllc}
\hline Subunit & \multicolumn{1}{c}{$\tau_{\text {des }}$ (msec) } & \multicolumn{1}{l}{ \%des } & Plateau/peak & $\tau_{\text {rec }}$ (msec) \\
\hline $\mathrm{A}_{\mathrm{i}}$, wt & $3.2 \pm 0.2$ & $97.9 \pm 0.6$ & $0.021 \pm 0.006$ & $155 \pm 11$ \\
$\mathrm{~A}_{\mathrm{l}}(\mathrm{R} 624 \mathrm{E})$ & $5.8 \pm 0.3$ & $57.6 \pm 4.0$ & $0.424 \pm 0.040$ & $127 \pm 6$ \\
$\mathrm{~B}_{\mathrm{i}}$, wt & $5.6 \pm 0.3$ & $96.5 \pm 0.8$ & $0.035 \pm 0.008$ & $21.8 \pm 2.0$ \\
$\mathrm{~B}_{\mathrm{i}}(\mathrm{R} 628 \mathrm{E})$ & $10.8 \pm 1.1$ & $14.5 \pm 1.5$ & $0.855 \pm 0.015$ & $\mathrm{ND}$ \\
$\mathrm{B}_{\mathrm{o}}, \mathrm{wt}$ & $1.8 \pm 0.2$ & $98.4 \pm 0.5$ & $0.016 \pm 0.005$ & $24.3 \pm 1.9$ \\
$\mathrm{~B}_{\mathrm{o}}(\mathrm{R} 628 \mathrm{E})$ & $3.3 \pm 0.2$ & $58.0 \pm 3.4$ & $0.420 \pm 0.034$ & $23.9 \pm 2.2$ \\
$6, \mathrm{wt}$ & $3.4 \pm 0.1$ & $99.6 \pm 0.2$ & $0.004 \pm 0.002$ & $1920 \pm 110$ \\
6 (R632E) & $6.8 \pm 0.7$ & $90.5 \pm 2.1$ & $0.095 \pm 0.021$ & $1070 \pm 120$ \\
6 (E631R) & $1.9 \pm 0.1$ & $99.9 \pm 0.1$ & $0.001 \pm 0.001$ & $1050 \pm 40$ \\
6 (E634R) & $3.5 \pm 0.3$ & $99.8 \pm 0.1$ & $0.002 \pm 0.001$ & $1620 \pm 110$
\end{tabular}

The time constants of desensitization $\left(\tau_{\text {des }}\right)$ and recovery from it $\left(\tau_{\text {rec }}\right)$ were obtained from single exponential fits (for details, see Materials and Methods). \%des and plateau/peak ratio are based on peak and steady-state current amplitudes. Values shown are the mean $\pm \operatorname{SEM}(n=4-10)$. We could not determine (ND) the recovery from desensitization for $G$ luR- $B_{i}(R 628 E)$ because of the small desensitizating current component. wt, Wild type.

The $\mathrm{R} \rightarrow$ E substitution introduces an additional negative side chain in the M3-S2 linker and underlies surface charge-like effects on $\mathrm{Ca}^{2+}$ permeability (Jatzke et al., 2003). The nondesensitizing phenotype therefore might arise because of divalent ions such as $\mathrm{Ca}^{2+}$ or $\mathrm{Zn}^{2+}$ more strongly interacting with this highly negative element. However, the extent of desensitization in GluR- $B_{i}$ (R628E) as well as wild-type channels was not significantly changed when recorded in the absence of divalent cations and in $100 \mu \mathrm{M}$ EDTA (Fig. 3C). Hence, the block of desensitization in GluR- $\mathrm{B}_{\mathrm{i}}(\mathrm{R} 628 \mathrm{E})$ is not caused by divalent cations and is probably caused by the $\mathrm{R} \rightarrow \mathrm{E}$ substitution itself.

\section{An electrostatic interaction underlies the disruption of desensitization}

To further address the mechanism underlying the nondesensitizing phenotype, we substituted various amino acids at the $\mathrm{R}$ position in the M3-S2 linker in GluR- $B_{i}$ and characterized the effect of these substitutions on desensitization properties (Fig. 4). All of the individual substitutions at the $\mathrm{R}$ position, like the $\mathrm{R} \rightarrow \mathrm{E}$ substitution, significantly slowed, albeit weakly, the rate of desensitization (Fig. 4A). On the other hand, only oppositely charged substitutions of this position significantly reduced the extent of desensitization (Fig. $4 B$ ), with the strongest reduction occurring for glutamate (R628E), followed by the aspartate (R628D) and the cysteine (R628C, which is $\sim 10 \%$ charged under physiological $\mathrm{pH})$ side chains. The positively charged histidine $(\mathrm{R} 628 \mathrm{H})$ also reduced $\%$ des $_{\text {СтZ }}$, but this effect was quite small $(94.0 \pm 1.2 \%$; $n=5)$ compared with wild type ( $97.7 \pm 0.4 \%, n=8)$. Surprisingly, the neutral alanine (R628A) and the polar glutamine

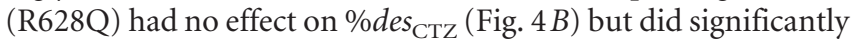
reduce the rate of recovery from desensitization (Fig. $4 C$ ). Overall, the results shown in Figure 4 suggest that the effect of $\mathrm{R} \rightarrow \mathrm{E}$ substitution on desensitization is at least in part attributable to electrostatic interactions.

\section{Substitutions of a negatively charged glutamate in the M3-S2 linker enhance desensitization}

If block of desensitization by the $\mathrm{R} \rightarrow \mathrm{E}$ substitution is attributable to electrostatic interactions, there may be other charged residues in the protein, presumably negatively charged, that complement the conserved $\mathrm{R}$. One potential candidate is within the M3-S2 linker itself. Indeed, adjacent to the conserved R in AMPAR and low-affinity KAR subunits is a negatively charged E (Fig. $1 B$ ), and these oppositely charged $\mathrm{E}$ and $\mathrm{R}$ residues could interact either in an intrasubunit or intersubunit state-dependent manner. In AMPAR subunits, either GluR- $\mathrm{A}_{\mathrm{i}}$ or $-\mathrm{B}_{\mathrm{i}}$, opposite charge 

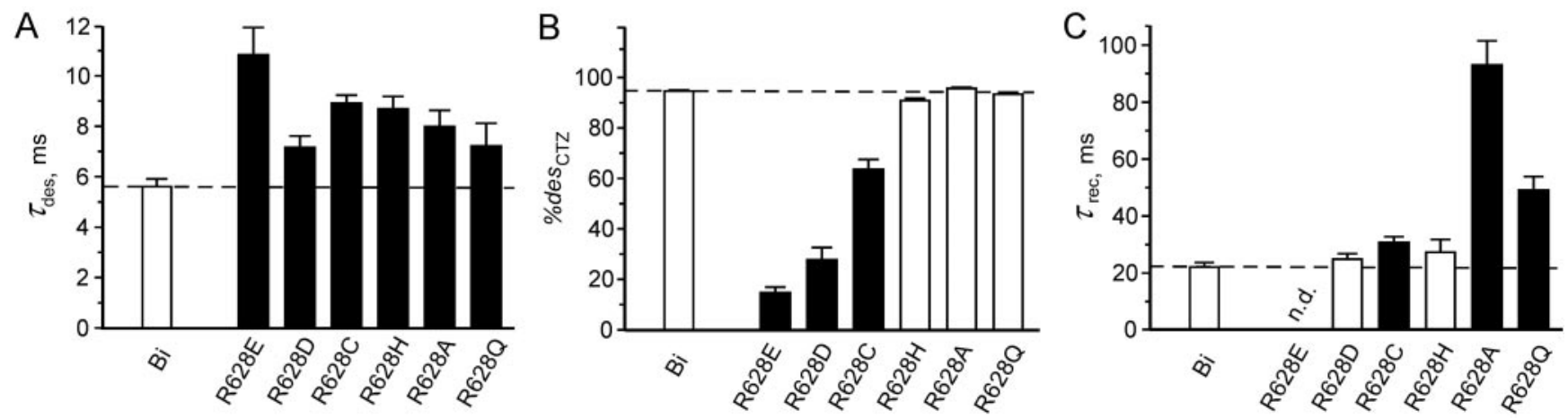

Figure 4. Desensitization properties of wild-type and mutant $G$ luR- $B_{i}$ channels. Average time constant of desensitization, $\tau_{\text {des }}(A)$, the extent of desensitization measured relative to the peak current in $\mathrm{CTZ}, \%$ des $_{\mathrm{CTZ}}(B)$, and the time constant of recovery from desensitization, $\tau_{\text {rec }}(C)$ measured for wild-type and mutant GluR-Bi channels are shown. $\tau_{\text {rec }}$ was not determined (n.d.) for R628E channels because of a small desensitizing component. In this and all subsequent figures, filled bars indicate values statistically different from those for wild type.

substitutions of this glutamate ( $\mathrm{E} \rightarrow \mathrm{R}$ substitution), yielded channels that even in the whole-cell mode had very small glutamate-activated current amplitudes (typically $<10 \mathrm{pA}$ compared with 3-5 nA for wild type). Hence, we could not consistently measure desensitization properties in outside-out patches. Notable, however, is that with added CTZ, peak current amplitudes were dramatically increased (Fig. $5 \mathrm{~A}$ ). The increase was maximal ( $\sim 700 \%)$ for the $\mathrm{E} \rightarrow \mathrm{R}$ substitution, although comparable effects were observed for other substitutions at this position (Fig. 5B). As discussed below, this dramatic current increase produced by CTZ arises at least in part because the $\mathrm{E} \rightarrow \mathrm{R}$ substitution enhances desensitization. Hence, without CTZ, E $\rightarrow$ $\mathrm{R}$-substituted channels are mainly in the desensitized state in the absence of glutamate or desensitize more rapidly than rates of channel opening, solution exchange, or both.

In contrast to AMPAR subunits, the $\mathrm{E} \rightarrow \mathrm{R}$ substitution in GluR-6 [GluR-6 (E631R)] expressed well. Currents through these channels showed a faster rate of desensitization and recovery from it and a greater extent of desensitization than wild type GluR-6 channels (also see Table 1, plateau/peak ratio). In addition, we found that the $\mathrm{E} \rightarrow \mathrm{R}$ substitution in a mutant GluR- $\mathrm{B}_{\mathrm{i}}$ subunit in which an asparagine $(\mathrm{N})$ occupies the $\mathrm{Q} / \mathrm{R}$-site [GluR$B_{i}(N)$ ] also showed reasonable current amplitudes. GluR- $B_{i}(N)$ channels themselves showed a slower rate of desensitization $\left(\tau_{\text {des }}\right.$ $\simeq 13 \mathrm{msec}$ ) and a reduced extent of desensitization (\%des $\simeq$ $92.5 \%)$ compared with GluR- $\mathrm{B}_{\mathrm{i}}(\mathrm{Q})$ channels $\left(\tau_{\text {des }} \simeq 5.6 \mathrm{msec}\right.$; $\%$ des $\simeq 96.5 \%$ ) (Fig. $5 C, D$ ). In the GluR- $\mathrm{B}_{\mathrm{i}}(\mathrm{N})$ background, the $\mathrm{R} \rightarrow \mathrm{E}$ substitution, like that in GluR- $\mathrm{B}_{\mathrm{i}}(\mathrm{Q})$, slowed the rate of desensitization by approximately twofold (Fig. 5C) and dramatically reduced the extent of desensitization (Fig. 5D). In contrast, the $\mathrm{E} \rightarrow \mathrm{R}$ substitution produced essentially opposite effects, significantly increasing the rate and extent of desensitization (Fig. $5 C, D)$.

In summary, an E residue in the M3-S2 linker, adjacent to the conserved $\mathrm{R}$, also affects desensitization. The effect of the $\mathrm{E} \rightarrow \mathrm{R}$ substitution is essentially opposite to that of the $\mathrm{R} \rightarrow \mathrm{E}$ substitution. Accordingly, the apparent glutamate affinity for channels with $\mathrm{E} \rightarrow \mathrm{R}$ substitution in the GluR- $\mathrm{B}_{\mathrm{i}}(\mathrm{Q})$ background was significantly reduced $\left(\mathrm{EC}_{50}=1.3 \pm 0.1 \mathrm{mM} ; n=5\right)$ compared with that in wild type $\left(\mathrm{EC}_{50} \simeq 134 \mu \mathrm{M}\right)$ (compare Fig. $3 C$ ). These results therefore support the idea that electrostatic interactions involving charged residues in the M3-S2 linker contribute to channel gating. On the other hand, the opposite effects of the $\mathrm{E} \rightarrow$ $\mathrm{R}$ and $\mathrm{R} \rightarrow \mathrm{E}$ substitutions on desensitization suggest that these electrostatic interactions are not confined to $\mathrm{E}$ and $\mathrm{R}$ themselves,
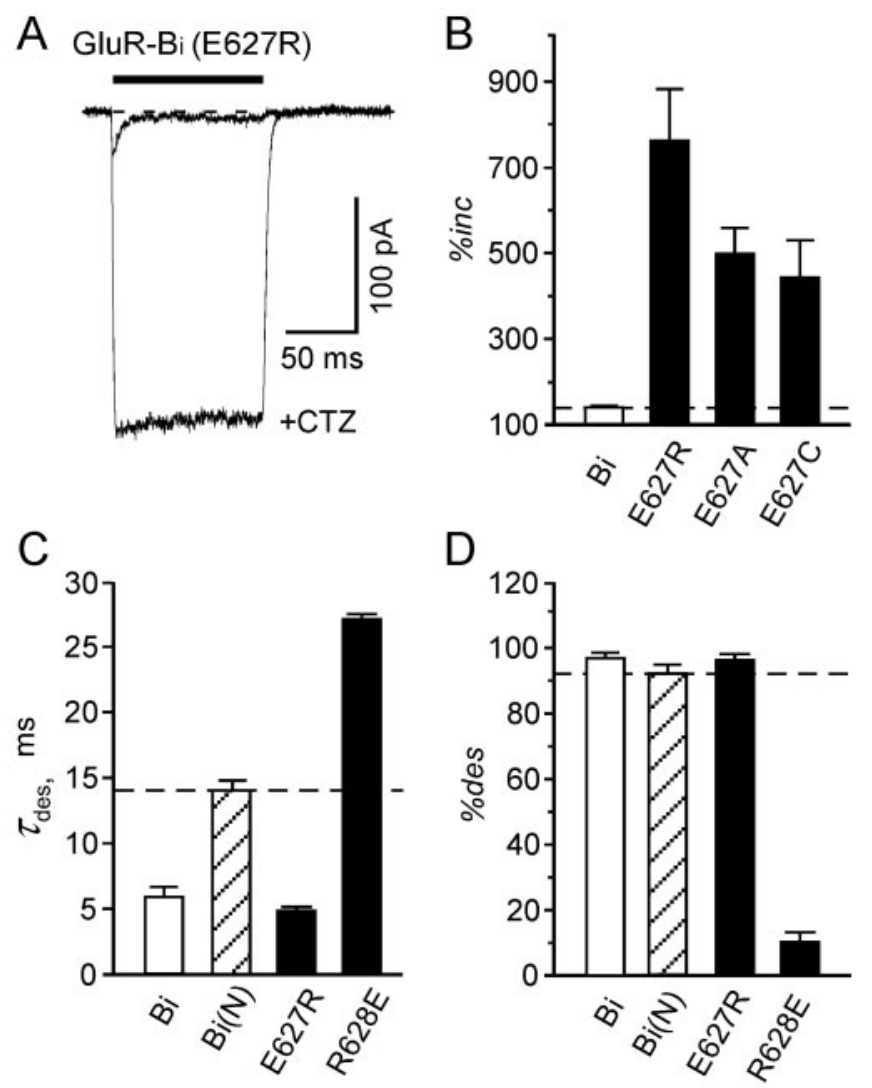

Figure 5. Effect of an $E \rightarrow R$ substitution on desensitization in GluR- $B_{i}$ channels. $A$, Superimposition of glutamate-activated currents for GluR- $B_{i}$ (E627R) channels ( $E \rightarrow R$ substitution) recorded in the absence or in the presence of $30 \mu \mathrm{m}$ CTZ. Currents were elicited by a $100 \mathrm{msec}$ application of glutamate ( $3 \mathrm{~mm}$; filled bar) at the holding potential of $-60 \mathrm{mV}$. $B$, Average values for $\%$ inc $c_{\text {peak }}$ for wild-type and mutant GluR-B $B_{i}$ channels. $C, D$, Average values for the rate of desensitization, $\tau_{\text {des }}(C)$, and the extent of desensitization measured relative to the peak current, \%des $(D)$, for wild-type channels $\left(B_{i}\right)$ and mutant channels containing an asparagine at the $Q / R$ site $\left[B_{i}(N)\right]$. Opposite charge substitution of $E$ and $R$ was made in the $B_{i}(N)$ background. Values for $B_{i}(N)$ are significantly different from those in $B_{i}(Q)$. Filled bars indicate values statistically different from those for GluR-B $B_{i}(N)$.

and some other complementary charge(s) located elsewhere in the protein have to be involved.

Orientation of the ER dipole is important to channel gating Although the adjacent opposite charged residues (E and R) in the M3-S2 linker have no net charge, they presumably form an elec- 


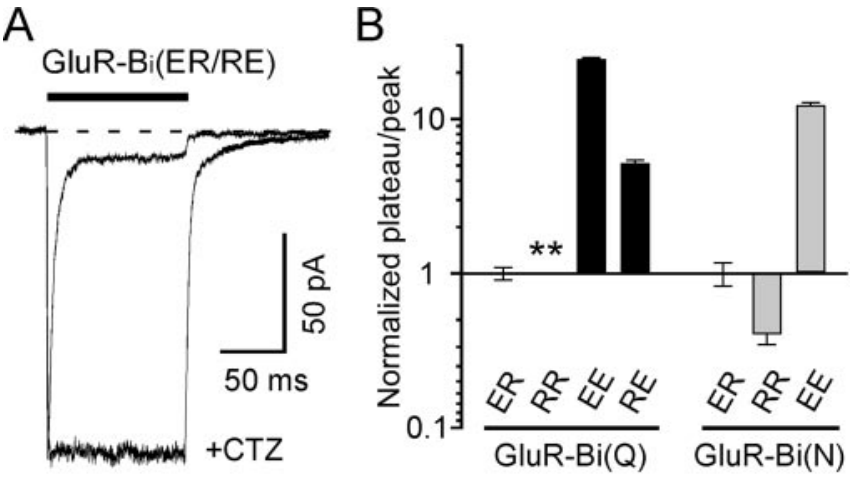

Figure 6. Opposite charge substitutions of both $E$ and R. A, Superimposition of glutamateactivated currents for GluR- $B_{i}$ (E627R/R628E) channels ( $E R \rightarrow$ RE substitution) recorded in the absence or in the presence of $30 \mu \mathrm{m}$ CTZ. Currents were elicited by a 100 msec application of glutamate ( $3 \mathrm{~mm}$; filled bar) at the holding potential of $-60 \mathrm{mV}$. B, Average values for the plateau/peak ratio normalized to wild type (ER channels) in the respective background of either GluR- $B_{i}(Q)$ or GluR- $B_{i}(N)$. Mutant channels include $R R(E \rightarrow R$ substitution), $E E(R \rightarrow E$ substitution), and $R E$ (ER $\rightarrow$ RE substituion). Values for $G l u R-B_{i}(Q)(R R)$ could not be determined because the peak current amplitudes were too small.

tric dipole. If charges complementary to E and R do indeed exist, changing the orientation of the ER dipole should affect gating in GluRs. To test this idea, we introduced opposite charge substitutions at both positions in the GluR- $\mathrm{B}_{\mathrm{i}}$ subunit $[\mathrm{ER} \rightarrow \mathrm{RE}$ substitution, GluR-B $\left.\mathrm{B}_{\mathrm{i}}(\mathrm{E} 627 \mathrm{R} / \mathrm{R} 628 \mathrm{E})\right]$. In ER $\rightarrow$ RE mutant channels (Fig. $6 A)$, the rate of desensitization $\left(\tau_{\text {des }}=5.7 \pm 0.3 \mathrm{msec} ; n=\right.$ $10)$ and recovery from it $\left(\tau_{\text {rec }}=18.2 \pm 1.5 \mathrm{msec} ; n=7\right)$ were indistinguishable from those in wild type $\left(\tau_{\mathrm{des}} \simeq 5.6 \mathrm{msec} ; \tau_{\mathrm{rec}} \simeq\right.$ $21.8 \mathrm{msec})$. On the other hand, the degree of desensitization, using CTZ as a reference (\%des $\left.{ }_{\mathrm{CTZ}}, 88.3 \pm 1.7 \% ; n=4\right)$, was significantly smaller than that in wild type ( $\sim 98 \%)$.

Figure $6 \mathrm{~B}$ summarizes the normalized plateau/peak ratio for charge substitutions in various GluR- $B_{\mathrm{i}}$ backgrounds. Compared with wild type (ER channels), the $\mathrm{E} \rightarrow \mathrm{R}$ (RR channels) and $\mathrm{R} \rightarrow$ $\mathrm{E}$ (EE channels) substitutions showed enhanced and decreased degrees of desensitization, respectively, with this effect quantitatively stronger for EE channels. Though the ER $\rightarrow$ RE-substituted channels (RE channels) also showed a reduced degree of desensitization, the effect was less pronounced than in EE channels. The results illustrated in Figure 6, therefore, suggest that the orientation of the ER dipole is important for normal channel function and support the idea of putative charges complementary to ER.

\section{Single amino acid differences in the linker regions do not underlie subunit specific effects on desensitization}

As an alternative approach to identify the complementary charge, we considered that the quantitative effect of the $\mathrm{R} \rightarrow \mathrm{E}$ substitution on \%des is subunit-specific (Fig. 2). In AMPARs, all three extracellularly positioned linker regions, S1-M1, M3-S2, and S2M4, as well as proximal parts of S1 and S2, are highly conserved with one exception. In the S2-M4 linker, the homologous position is occupied by an aspartate (D778) in GluR- $\mathrm{A}_{\mathrm{i}}$ and a glutamate (E782) in GluR- $B_{i}$. Nevertheless, in a double-mutant channel in which this aspartate in GluR- $\mathrm{A}_{\mathrm{i}}$ was mutated to a glutamate in the $\mathrm{R} \rightarrow \mathrm{E}$ background, GluR-A $\mathrm{A}_{\mathrm{i}}$ (R624E/D778E), the extent of desensitization was the same as that in GluR-A $\mathrm{A}_{\mathrm{i}}(\mathrm{R} 624 \mathrm{E})$ rather than being like that in GluR- $\mathrm{B}_{\mathrm{i}}$ (R628E) (data not shown). Hence, no obvious single charged amino acid difference in the linker regions underlies the subunit specific effect of the $\mathrm{R} \rightarrow \mathrm{E}$ substitution.
Subunit-specific and state-dependent reactivity of cysteines substituted in the M3-S2 linker

The subunit-specific differences between AMPAR subtypes appear not to be attributable to a charge difference but rather may reflect structural differences in the M3-S2 linker. To address this idea, we compared glutamate-activated current amplitudes, in mutant GluR- $\mathrm{A}_{\mathrm{i}}$ and GluR- $\mathrm{B}_{\mathrm{i}}$ channels containing cysteines substituted at the E and R positions, before $\left(I_{\text {pre }}\right)$ and after $\left(I_{\text {post }}\right)$ the extracellular application of the positively charged methanethiol sulfonate (MTS) reagent MTSET (Fig. 7A). We were also interested in the state dependence of reactivity, so we applied MTSET when channels were mainly (but not exclusively) in the open (top trace), closed (middle trace), and desensitized (bottom trace) states. The maximal occupation of the various states was achieved by applying MTSET in the continuous presence of Glu (1 mM) and saturating concentrations of CTZ ( $50 \mu \mathrm{M}$; open state, $\mathrm{O}$ ), in the absence of glutamate and in the presence of the competitive AMPAR antagonist CNQX (10 $\mu \mathrm{M}$; closed state, C), and, finally, in the continuous presence of Glu but in the absence of CTZ (desensitized state, D). However, the distinction between states is by no means absolute. For example, the $\mathrm{R} \rightarrow \mathrm{C}$ substitution in GluR-B $\mathrm{i}_{\mathrm{i}}\left[\right.$ GluR-B $\mathrm{B}_{\mathrm{i}}$ (R628C)] disrupts desensitization (Fig. 4B), indicating that even in the absence of CTZ (presence of glutamate), the channels will spend considerable time in the open state.

Figure $7 B$ summarizes the mean percentage change in current amplitude after the application of MTSET for wild-type and cysteine-substituted GluR- $A_{i}$ and GluR- $B_{i}$ channels. For wildtype channels, MTSET had no persistent effects on current amplitudes under any of the conditions. On the other hand, in cysteine-substituted mutant channels, the effect of MTSET on current amplitude was strongly subunit specific and state dependent. At the E position, MTSET altered current amplitudes under all conditions for GluR- $B_{i}$, whereas it produced a significant change only when applied in the desensitized state for GluR- $\mathrm{A}_{\mathrm{i}}$. In contrast, at the R position, MTSET did not alter current amplitude under any conditions in GluR- $\mathrm{A}_{\mathrm{i}}$, whereas it produced a significant change in GluR- $\mathrm{B}_{\mathrm{i}}$ only when applied in the desensitized state.

The results with the homologous positions in GluR- $\mathrm{A}_{\mathrm{i}}(\mathrm{E} 623$ and R624) and GluR- $\mathrm{B}_{\mathrm{i}}$ (E627 and R628) suggest that there are structural differences in the M3-S2 linker between different GluR subtypes. Additionally, the state-dependent reactivity of GluR-A (E623C) and GluR- $B_{i}$ (R628C) with MTSET suggests that conformations of the M3-S2 linker are different in the nonconducting closed and desensitized states.

\section{Discussion}

GluR desensitization is an important mechanism shaping excitatory postsynaptic potentials in the brain (Jones and Westbrook, 1996; Glavinovic and Rabie, 1998). As a gating process, desensitization originates in the ligand-binding domain and propagates to the ion channel. Our results represent the first identification of residues outside the ligand-binding domain that can alter desensitization in non-NMDAR channels and suggest that electrostatics involving in part charged residues in the M3-S2 linker contribute to gating in GluRs.

\section{Charged residues in the M3-S2 linker influence channel gating}

Opposite charge substitutions of two adjacent charged residues, a glutamate (E627 in GluR- $\mathrm{B}_{\mathrm{i}}$ ) and a conserved arginine (R628 in GluR- $\mathrm{B}_{\mathrm{i}}$ ), strongly affected desensitization in both AMPA and 
KA GluR subtypes (Figs. 2, 5; Table 1). These two residues are positioned outside the ligand-binding domain (Armstrong et al., 1998; Armstrong and Gouaux, 2000) being located N-terminal to S2 (see Fig. 1). On the other hand, substitutions of these residues in AMPARs (Jatzke et al., 2003) and of homologous positions in the NMDAR NR1 subunit (Watanabe et al., 2002) affect $\mathrm{Ca}^{2+}$ permeation, suggesting that they are associated with the ion conduction pathway. Nevertheless, ER is positioned four amino acid residues external to SYTANLAAF, a motif forming the most extracellular part of the channel (Sobolevsky et al., 2003). We therefore refer to the location of ER between the ligandbinding domain and the ion channel as the M3-S2 linker.

The reduced extent of desensitization in $\mathrm{R} \rightarrow$ E-substituted GluR- $\mathrm{B}_{\mathrm{i}}$ channels $(\%$ des $\simeq 14 \%$; compared with $\%$ des $\simeq$ $97 \%$ in wild type) is comparable with that produced by the leucine-to-tyrosine $(\mathrm{L} \rightarrow \mathrm{Y}$ ) substitution in the ligand-binding domain (\%des $\simeq 8-10 \%)$ in the same background (Stern-Bach et al., 1998; Sun et al., 2002). The $\mathrm{L} \rightarrow$ Y substitution as well as binding of CTZ block desensitization by stabilizing a dimer interface in the ligand-binding domain (Sun et al., 2002), slowing the rate of desensitization by nearly 30-fold (Robert et al., 2001; Sun et al., 2002). In contrast, the R $\rightarrow$ E substitution is located well outside the ligand-binding domain and slows the rate of desensitization by only approximately twofold (Table 1). Therefore, the $\mathrm{L} \rightarrow \mathrm{Y}$ and $\mathrm{R} \rightarrow \mathrm{E}$ substitutions apparently block desensitization in GluRs by fundamentally different mechanisms.

\section{Charged residues alter channel gating via electrostatic interactions}

Channels containing an opposite charge substitution of a conserved arginine ( $\mathrm{R} \rightarrow \mathrm{E}$ substitution, EE channels) in the M3-S2 linker showed a reduced degree of desensitization (Figs. 2, 3; Table 1). Neutralizing substitutions (EA and EQ channels), although not changing significantly the degree of desensitization, strongly slowed down the rate of recovery from desensitization (Fig. 4C). An opposite charge substitution of E, a residue adjacent to the conserved $\mathrm{R}(\mathrm{E} \rightarrow \mathrm{R}$ substitution, $\mathrm{RR}$ channels), produced effects essentially opposite to that of the $\mathrm{R} \rightarrow \mathrm{E}$ substitution (Figs. $5,6)$, yet mutant channels in which both charges were reversed (ER $\rightarrow$ RE substitution) still showed gating differences (Fig. 6). Together these results suggest that electrostatics as contributed by the charges or the dipole of ER or both in the M3-S2 linker influence gating in GluRs.

The electrostatic interactions involving $\mathrm{E}$ and $\mathrm{R}$ imply the existence of closely located charges that interact with each other in a state-dependent manner (Fig. 7). The possibility of intrasubunit or intersubunit interactions involving only $\mathrm{E}$ and $\mathrm{R}$ themselves seems unlikely because opposite charge substitutions at either position (EE or RR channels) produced opposite effects on
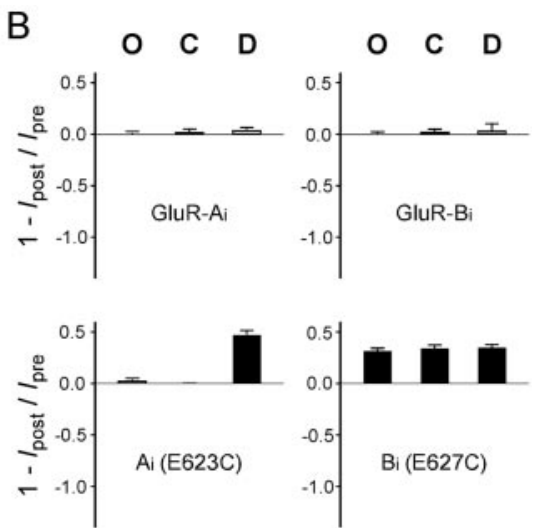

$\mathrm{Bi}(\mathrm{R} 628 \mathrm{C})$

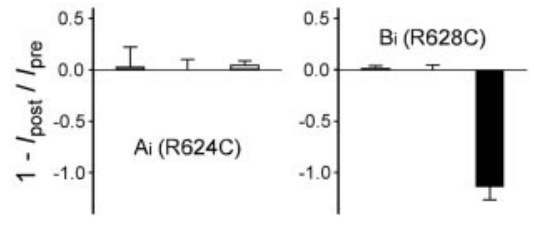

Figure 7. State-dependent effect of a sulfhydryl-specific reagent on glutamate-activated currents in cysteine-substituted AMAR channels. $A$, Protocols to measure the state dependence of reactivity. Whole-cell currents recorded from Xenopus oocytes

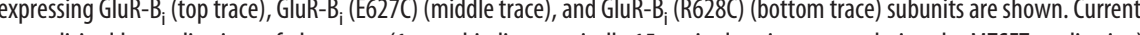
glutamate and in the presence of the competitive antagonist CNQX (10 $\mu \mathrm{m}$; shaded box, middle trace), or just in the presence of glutamate (bottom trace). During these different applications, we assume that the predominant channel state is open ( 0 ; top (C, middle trace), or desensitized ( $D$; bottom trace).Current amplitudes were measured either before $\left(I_{\text {pre }}\right)$ or after and GluR- $B_{i}$ (right column) channels. Up- and down-pointing bars indicate inhibition and potentiation of glutamate-activated currents, respectively. Filled bars indicate a significant difference between $I_{\text {post }}$ and $I_{\text {pre }}(n=3-8)$.

channel gating rather than the anticipated comparable effect (Fig. 6). Alternatively (Fig. 8), a charge complementary to E and R could exist in other parts of the GluR protein. The complementary charge may arise from charged or polar residues in other linkers (S1-M1 or S2-M4), proximal parts of the ligand-binding domain, or both, as well as from dipole charges of $\alpha$-helices in the transmembrane (segments M1, M3, or M4) or ligand-binding domains.

Without some means of constraining mutagenesis, the number of possibilities presented by these latter alternatives is quite large. Indeed, just within the S1-M1 and S2-M4 linkers, there are 7 negatively charged and 10 polar residues. Therefore, additional information about the structure and positioning of all linker regions as well as proximal parts of the ligand-binding domain will be needed to constrain mutagenesis. Nevertheless, identifying this complementary charge(s) would help clarify the statedependent conformational changes occurring in both the ligandbinding domain and ion channel during desensitization. Similarly, because desensitization is modified at the levels of the ligand-binding domain and the M3-S2 linker by fundamentally different mechanisms, it would provide insights into the modular design of GluRs as well as the order of molecular events during gating.

\section{Contribution of the M3-S2 linker in different GluR subunits to gating}

In all non-NMDAR subunits, channels containing the $\mathrm{R} \rightarrow \mathrm{E}$ substitution showed a reduced degree of desensitization (Fig. 2, Table 1). In terms of the \%des, this effect was strongest in the 
Closed
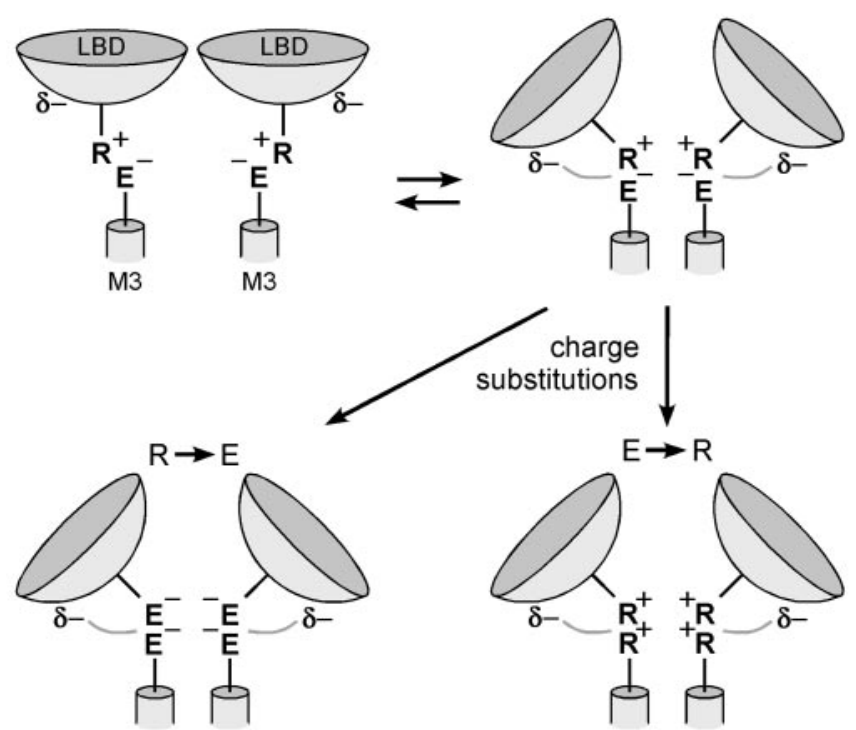

unfavorable interaction

reduced desensitization
Desensitized

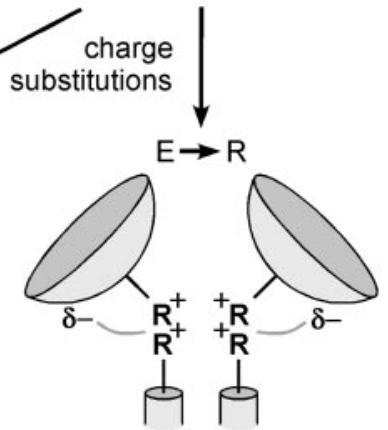

favorable interaction increased desensitization
Figure 8. Possible state-dependent electrostatic interactions in GluRs. The diagram illustrates possible electrostatic interactions between $\mathrm{E}$ and $\mathrm{R}$ in the $\mathrm{M} 3-\mathrm{S} 2$ linker and a complimentary charge in other parts of the protein. This complimentary charge may arise from negative or polar residues in other extracellularly located linkers or from proximal parts of the ligandbinding domain (LBD). Alternatively, it may arise from $\alpha$-helical dipoles. Because of subunitand subtype-specific structural differences, which may be quite small, $E$ and $R$ and the putative complimentary charge may show various degrees of proximity in the desensitized state, leading to differences in the degree of desensitization in wild-type channels.

GluR- $B_{i}$ background, but the fold increase for plateau/peak ratios was approximately the same in all backgrounds (Table 1). Indeed, the \%des for wild-type GluR-6, GluR-A $\mathrm{A}_{\mathrm{i}}$, and GluR- $\mathrm{B}_{\mathrm{i}}$ (Table 1) decreased in parallel with the ratio of the rate of exit from $(\gamma)$ and entry into $(\delta)$ desensitization $\left[\gamma / \delta \simeq 10^{-5}-10^{-4}\right.$ for GluR-6

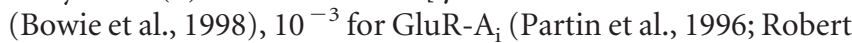
and Howe, 2003), and $10^{-2}-10^{-1}$ for GluR- $B_{i}$ (Koike et al., 2000)]. In addition, the subunit-specific effect of the $R \rightarrow E$ substitution can be simulated by the same modification of the wildtype models, specifically increasing the rate of exit from the desensitized state by $\sim 10^{2}$ times as well as decreasing the rate of agonist dissociation $\left(k_{\text {off }}\right)$ by $\sim 10$ times (data not shown). Hence the electrostatic interactions involving charged residues in the M3-S2 linker contribute to gating in all non-NMDAR subunits and subtypes similarly, but the visible effect on desensitization depends on the extent of desensitization for the corresponding wild type.

Structurally, the difference in the maximal degree of desensitization may reflect either a difference in the secondary structure or more likely a difference in the spatial arrangement of the M3-S2 linker relative to other domains, specifically those containing a complementary charge (Fig. 8). The differential reactivity of MTSET with cysteine substituted at E and R positions in GluR-A and GluR-B channels (Fig. 7) supports the latter alternative. In AMPAR subunits, transmembrane domains and associated linkers are highly conserved (nearly 100\% sequence identity, with the only exception being in the intracellularly located M1-M2 linker), suggesting that the structural difference in the M3-S2 linker between non-NMDAR subunits and subtypes is probably not attributable to differences in the transmembrane domains but rather to the ligand-binding domain. Supporting this idea is the differential effect of the $\mathrm{R} \rightarrow \mathrm{E}$ substitution on desensitization in the flip and flop variants of GluR-B (Table 1). Hence the structure of the ion channel at the level of the M3-S2 linker parallels that of the ligand-binding domain. This conclusion agrees with recent results suggesting that the outer pore of the AMPAR channel has a rotational symmetry similar to that of the ligand-binding domain (Sobolevsky et al., 2004).

\section{Different structures of the M3-S2 linker in the closed and desensitized states}

The M3-S2 linker is a polypeptide of unknown secondary structure. One end of M3-S2 is connected to the S2 domain, a part of the ligand-binding domain with the structure solved by crystallography (Armstrong et al., 1998; Armstrong and Gouaux, 2000). On the other side, M3-S2 is connected to the M3 segment that, based on sidedness of accessibility to MTS reagents, is $\alpha$-helical (Sobolevsky et al., 2003). The secondary structure of the M3-S2 linker itself may be difficult to infer from the pattern of accessibility because this region is outside the transmembrane portion of GluR and hence may be water-accessible on all sides. Nevertheless, it seems likely that at least part of the M3-S2 linker is extended, specifically that part around ER.

Previous results have suggested that the M3-S2 linker has a different conformation in the open and closed states (Sobolevsky et al., 2003). The accessibility pattern shown in Figure $7 B$ suggests that the nonconducting closed and desensitized states of the AMPAR channel are also structurally different at the linker level. Of course, this interpretation is limited by the assumptions of the substituted cysteine accessibility method (Karlin and Akabas, 1998), and at present it is unclear how far into the pore this asymmetry between the closed and desensitized conformations exists. Future experiments will be needed to further delineate the structural similarities and differences between the open, closed, and desensitized states.

\section{References}

Armstrong N, Gouaux E (2000) Mechanisms for activation and antagonism of an AMPA-sensitive glutamate receptor: crystal structures of the GluR2 ligand binding core. Neuron 28:165-181.

Armstrong N, Sun Y, Chen GQ, Gouaux E (1998) Structure of a glutamatereceptor ligand-binding core in complex with kainate. Nature 395:913-917.

Banke TG, Greenwood JR, Christensen JK, Liljefors T, Traynelis SF, Schousboe A, Pickering DS (2001) Identification of amino acid residues in GluR1 responsible for ligand binding and desensitization. J Neurosci 21:3052-3062.

Beck C, Wollmuth LP, Seeburg PH, Sakmann B, Kuner T (1999) NMDAR channel segments forming the extracellular vestibule inferred from the accessibility of substituted cysteines. Neuron 22:559-570.

Bowie D, Lange GD, Mayer ML (1998) Activity-dependent modulation of glutamate receptors by polyamines. J Neurosci 18:8175-8185.

Dingledine R, Borges K, Bowie D, Traynelis SF (1999) The glutamate receptor ion channels. Pharmacol Rev 51:7-61.

Glavinovic MI, Rabie HR (1998) Monte Carlo simulation of spontaneous miniature excitatory postsynaptic currents in rat hippocampal synapse in the presence and absence of desensitization. Pflügers Arch 435:193-202.

Jatzke C, Hernandez M, Wollmuth LP (2003) Extracellular vestibule determinants of $\mathrm{Ca}^{2+}$ influx in $\mathrm{Ca}^{2+}$-permeable AMPA receptor channels. J Physiol (Lond) 549:439-452.

Jones KS, VanDongen HM, VanDongen AM (2002) The NMDA receptor M3 segment is a conserved transduction element coupling ligand binding to channel opening. J Neurosci 22:2044-2053.

Jones MV, Westbrook GL (1996) The impact of receptor desensitization on fast synaptic transmission. Trends Neurosci 19:96-101. 
Karlin A, Akabas MH (1998) Substituted-cysteine accessibility method. Methods Enzymol 293:123-145.

Kash TL, Jenkins A, Kelley JC, Trudell JR, Harrison NL (2003) Coupling of agonist binding to channel gating in the $\mathrm{GABA}(\mathrm{A})$ receptor. Nature 421:272-275.

Kohda K, Wang Y, Yuzaki M (2000) Mutation of a glutamate receptor motif reveals its role in gating and delta 2 receptor channel properties. Nat Neurosci 3:315-322.

Kohler M, Burnashev N, Sakmann B, Seeburg PH (1993) Determinants of $\mathrm{Ca}^{2+}$ permeability in both TM1 and TM2 of high affinity kainate receptor channels: diversity by RNA editing. Neuron 10:491-500.

Koike M, Tsukada S, Tsuzuki K, Kijima H, Ozawa S (2000) Regulation of kinetic properties of GluR2 AMPA receptor channels by alternative splicing. J Neurosci 20:2166-2174.

Kuner T, Wollmuth LP, Karlin A, Seeburg PH, Sakmann B (1996) Structure of the NMDA receptor channel M2 segment inferred from the accessibility of substituted cysteines. Neuron 17:343-352.

Kuner T, Beck C, Sakmann B, Seeburg PH (2001) Channel-lining residues of the AMPA receptor M2 segment: structural environment of the $Q / R$ site and identification of the selectivity filter. J Neurosci 21:4162-4172.

Kuner T, Seeburg PH, Robert Guy H (2003) A common architecture for $\mathrm{K}^{+}$ channels and ionotropic glutamate receptors? Trends Neurosci 26:27-32.

Larsson HP, Elinder F (2000) A conserved glutamate is important for slow inactivation in $\mathrm{K}^{+}$channels. Neuron 27:573-583.

Mansour M, Nagarajan N, Nehring RB, Clements JD, Rosenmund C (2001) Heteromeric AMPA receptors assemble with a preferred subunit stoichiometry and spatial arrangement. Neuron 32:841-853.

Mosbacher J, Schoepfer R, Monyer H, Burnashev N, Seeburg PH, Ruppersberg JP (1994) A molecular determinant for submillisecond desensitization in glutamate receptors. Science 266:1059-1062.

Partin KM (2001) Domain interactions regulating AMPA receptor desensitization. J Neurosci 21:1939-1948.

Partin KM, Patneau DK, Winters CA, Mayer ML, Buonanno A (1993) Selective modulation of desensitization at AMPA versus kainate receptors by cyclothiazide and concanavalin A. Neuron 11:1069-1082.

Partin KM, Patneau DK, Mayer ML (1994) Cyclothiazide differentially modulates desensitization of alpha-amino-3-hydroxy-5-methyl-4isoxazolepropionic acid receptor splice variants. Mol Pharmacol 46:129-138.

Partin KM, Bowie D, Mayer ML (1995) Structural determinants of allosteric regulation in alternatively spliced AMPA receptors. Neuron 14:833-843.

Partin KM, Fleck MW, Mayer ML (1996) AMPA receptor flip/flop mutants affecting deactivation, desensitization, and modulation by cyclothiazide, aniracetam, and thiocyanate. J Neurosci 16:6634-6647.

Robert A, Howe JR (2003) How AMPA receptor desensitization depends on receptor occupancy. J Neurosci 23:847-858.

Robert A, Irizarry SN, Hughes TE, Howe JR (2001) Subunit interactions and AMPA receptor desensitization. J Neurosci 21:5574-5586.

Seeburg PH (1993) The Trends Neurosci/TiPS Lecture. The molecular biology of mammalian glutamate receptor channels. Trends Neurosci 16:359-365.

Sobolevsky AI, Beck C, Wollmuth LP (2002) Molecular rearrangements of the extracellular vestibule in NMDAR channels during gating. Neuron 33:75-85

Sobolevsky AI, Yelshansky MV, Wollmuth LP (2003) Different gating mechanisms in glutamate receptor and $\mathrm{K}^{+}$channels. J Neurosci 23:7559-7568.

Sobolevsky AI, Yelshansky MV, Wollmuth LP (2004) The outer pore of the glutamate receptor channel has 2 -fold rotational symmetry. Neuron 41:367-378.

Stern-Bach Y, Russo S, Neuman M, Rosenmund C (1998) A point mutation in the glutamate binding site blocks desensitization of AMPA receptors. Neuron 21:907-918.

Sun Y, Olson R, Horning M, Armstrong N, Mayer M, Gouaux E (2002) Mechanism of glutamate receptor desensitization. Nature 417:245-253.

Watanabe J, Beck C, Kuner T, Premkumar LS, Wollmuth LP (2002) DRPEER: a motif in the extracellular vestibule conferring high $\mathrm{Ca}^{2+}$ flux rates in NMDA receptor channels. J Neurosci 22:10209-10216.

Wollmuth LP, Kuner T, Seeburg PH, Sakmann B (1996) Differential contribution of the NR1- and NR2A-subunits to the selectivity filter of recombinant NMDA receptor channels. J Physiol (Lond) 491:779-797. 